\title{
\begin{tabular}{r|r} 
TMS Releases Technical Report; Partnership \\
\hline
\end{tabular} Announced for New MiNES Event; 3DMS Publishing Opportunity in TMS Journals \\ themagazine
}

\section{member news}

Share the good news

about your professional

accomplishments!

Contact Kaitlin Calva,

JOM Magazine

Managing Editor,

at kcalva@tms.org.

Please note that only

news submitted by

current TMS members

will be considered.
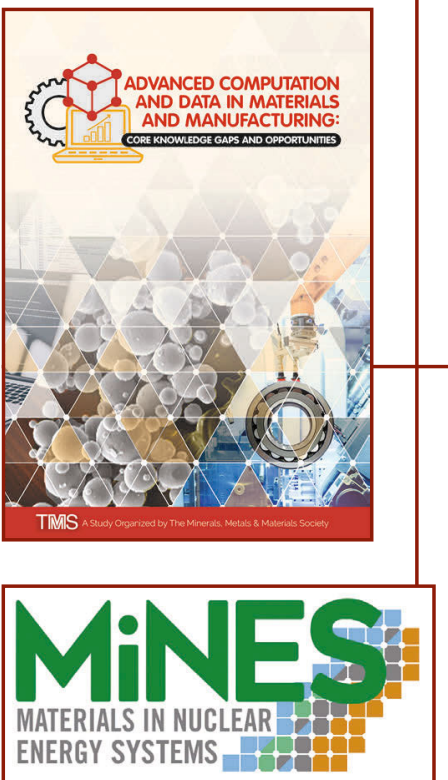

\section{New TMS Study Available for Download}

Advanced Computation and Data in Materials and Manufacturing: Core Knowledge Gaps and Opportunities, the latest technical report from TMS, was released on October 12, 2018. Organized by TMS on behalf of the U.S. National Science Foundation, the report is available for free download at www.tms.org/CoreKnowledge.

Developed as a roadmap for enhanced education and training initiatives, this report examines the core knowledge that needs to be developed in the workforce to fully realize the game-changing potential of advanced computational tools and data-driven methods in materials and manufacturing. Building on the contributions of nearly 35 leading experts who participated in a facilitated workshop in March 2018, Advanced Computation and Data in Materials and Manufacturing identifies 38 technical gaps. It also provides detailed discussion and action plans to close the six highest priority gaps:

- Coupling Simulations and Experiments

- Data-Driven Approaches
- Digital Data Infrastructure

- Digital Representation and

Visualization

- Predictive Multiscale Modeling

- Uncertainty Quantification and Propagation

Additionally, the report presents recommendations that address overarching community issues, including a lack of cross-disciplinary collaboration, the disconnect among stakeholder groups, and inadequate training opportunities. Several case studies are provided to introduce how groups are currently addressing knowledge gap areas, as well as illustrate some of their ongoing challenges.

Advanced Computation and Data in Materials and Manufacturing is the latest in a series of impactful technical reports that TMS has led on topics critical to the advancement of the minerals, metals, and materials fields. To access previous TMS technical reports and for details on upcoming publications visit the TMS Studies homepage at www.tms.org/Studies.

\section{TMS Co-Sponsors New MiNES Event}

TMS is co-sponsoring a new conference, Materials in Nuclear Energy Systems (MiNES), with the American Nuclear Society (ANS). Set for October 6-10, 2019, in Baltimore, Maryland, the event was created to serve the fission reactor materials community that grew out of the biannual symposia held at the TMS Annual Meeting \& Exhibition (Microstructure Processes in Irradiated Materials) and the ANS Annual Meeting (Nuclear Fuels and Structural Materials). The 2019 event will serve as the first in a series to be held every other year, with ANS and TMS alternating sponsorship of the conference.

Janelle Wharry, assistant professor at Purdue University and TMS member, is leading the organization of MiNES 2019 as general chair. "MiNES will establish a home for the nuclear and irradiated materials community," Wharry said. "MiNES will bring us together for the first time, which will strengthen collaborations and the network within our community."

MiNES 2019 is currently seeking abstracts in seven technical areas, including: irradiation damage; irradiated microstructures; mechanical properties of irradiated materials; radiation effects simulation and evaluation techniques; integrated phenomena in reactor materials; advanced alloys and materials for nuclear systems; advanced fuels and actinide materials; and nuclear fuel cycles. The deadline for submissions is April 1, 2019.

For additional details on the program, organizing committee, and abstract submission instructions, visit mines.ans.org. 


\section{DMS Topical Collection Seeks Article Submissions}

The TMS journals Integrating Materials and Manufacturing Innovation, JOM, and Metallurgical and Materials Transactions $A$ are planning coordinated topical collections on the subject of $3 \mathrm{D}$ materials science. This unique collaboration, introduced at the 4th International Congress on 3D Materials Science (3DMS 2018) in June, is open to the public and will be accepting submissions on various aspects of this topic through March 1, 2019. Papers will be published in the January-March 2020 issues of the journals.

Each journal will focus on a different aspect of 3D materials science:

\section{Integrating Materials and Manufacturing Innovation}

About this Collection: Submissions are encouraged on new experimental tools and techniques for 3D materials science, data descriptor articles of novel data sets, 3D data processing and reconstruction algorithms, and descriptions of software for simulation.

How to Submit: Go to https://www .editorialmanager.com/immj/ and choose "Additional Information" in the New Submission Menu and indicate the "3D Materials Science" topical collection.

\section{JOM}

About this Collection: Submissions are encouraged from academia, government laboratories, and industry on the application of materials modeling and processingmicrostructure-property relationships in 3D to manufacturing processes.

How to Submit: Go to https:/www .editorialmanager.com/jomj/ and select "2001: 3D Materials Science" in the dropdown menu for Section/Category.

\section{Metallurgical and Materials Transactions $A$}

About this Collection: Submissions are encouraged on innovative characterization approaches and algorithms, computational simulations and property prediction models that employ 3D data, and new insights on materials structure and behavior that arise from 3D data.

How to Submit: Go to https://mmta .msubmit.net and choose the Symposium article type and add "3D Materials Science" in the manuscript comments box. Include a cover letter that indicates the topical collection.

To learn more about how to submit papers to all TMS journals, visit www.tms.org/Journals.

\section{TMS Teams Up with Acta Materialia for New Scholarship}

A new scholarship opportunity for Material Advantage students, the Acta Materialia Inc. Undergraduate Scholarship, is now available through a partnership between TMS and Acta Materialia Inc. The scholarship is supported by the generosity of Acta Materialia Inc. and issued under the TMS Foundation.

The award is open to undergraduate students who are majoring in metallurgical engineering or materials science and engineering, or undergraduate students who have a significant interest in the materials area. The inaugural recipients will accept their honors during the TMS-AIME Awards Ceremony held at the TMS 2019 Annual Meeting \& Exhibition this March in San Antonio, Texas. Look to the article "Presenting the 2019 TMS Scholars" also in this issue for words of thanks from each scholar.

Applications for the 2020 awards are now being accepted through March 15, 2019.
Along with their completed TMS scholarship application, three recommendations, and a current transcript with GPA, applicants must also submit a personal statement that describes any unique educational experiences, career plans, leadership experiences, involvement in Material Advantage chapter, and/or community involvement. Relevance of the applicant's coursework will be considered when determining an award recipient. The scholars will each receive $\$ 5,000$ and an additional $\$ 500$ stipend to help cover travel expenses to attend the TMS Annual Meeting \& Exhibition to receive their awards.

Completed application packages can be submitted to Bryn Simpson, TMS Membership and Volunteer Program Manager, at bsimpson@tms.org. Submission forms and additional information can be found in the Scholarships page of the Students section of the TMS website, located under the Membership tab, or at www.tms.org/Students.
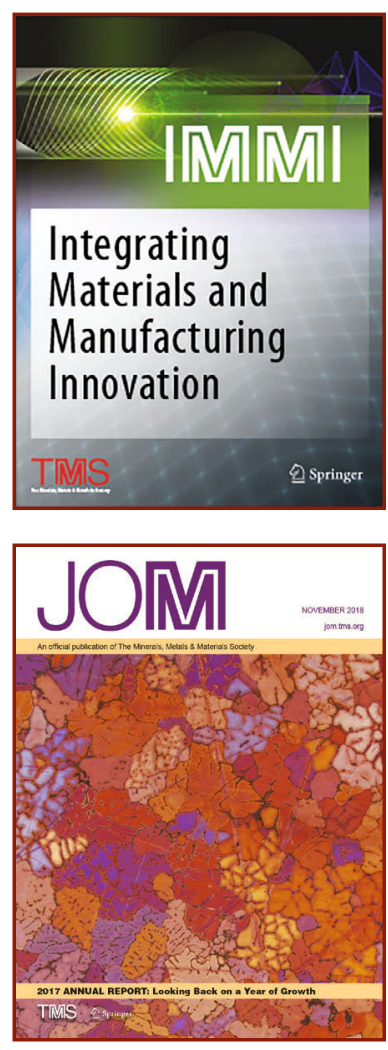

Metallurgical and Materials Transactions (A) Physical Metallurgy and

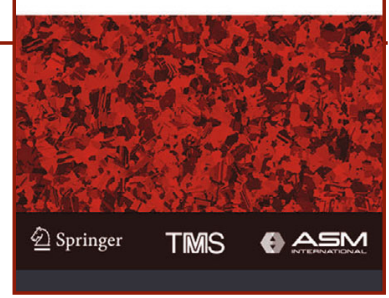




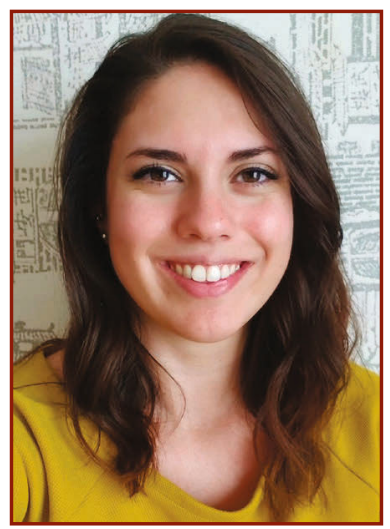

Michele L. Bustamante

\section{Congressional Fellow Update}

\begin{abstract}
Michele L. Bustamante is bringing her voice and experience as a sustainability scientist and materials researcher to the office of Senator Ed Markey (D-MA) as the 2018-2019 Congressional Science and Engineering Fellow. Bustamante began her one-year term in September 2018, and accepted placement in Markey's office after a two-week science policy orientation and interviews with multiple offices to find the best fit. Her activities in this role may include conducting legislative work, assisting in congressional hearings, or preparing briefs and writing speeches.

If you are also looking for an immersive public policy learning experience, apply for the 2019-2020 Congressional Science and Engineering Fellowship Program, now accepting applications. The program is sponsored jointly by TMS and the Materials Research Society (MRS) and is administered through the American Association for the Advancement of Science.
\end{abstract} 2019.
To be considered for the position, applicants must have a record of success in research or scholarship in a field relevant to materials science, while also demonstrating a strong interest in applying scientific and technical knowledge to U.S. public policy issues. Applicants are expected to be members (or applicants for membership) of TMS or MRS, and must have a Ph.D. by September 1, 2019, the fellowship's starting date. U.S. citizenship is not required, but applicants must be authorized to work in the United States.

For details on applying for the Congressional Fellow program, as well as a listing of past fellows and their JOM articles highlighting what they learned during their time in Washington D.C., visit the TMS/MRS Congressional Science and Engineering Fellowship page, accessed under the Outreach tab on the TMS website.

If you have questions about the application process or other aspects of the program, contact Mary Samsa, TMS Foundation and Public Affairs Manager, at msamsa@tms.org.

\section{TMS Welcomes New Members}

\section{The TMS Board of Directors approved professional membership for the following individuals at its October 2018 meeting. Please join us in congratulating and welcoming them to all the privileges and benefits of TMS membership.}

Acar, Pinar; Virginia Polytechnic Institute, United States

Adams, Beryn; Lanxess Sybron, United States

Alvarado, Manuel; United States

Anthony, Mason B.; United States

Bahadar, Ali; King Abdulaziz UniversityRabigh, Saudi Arabia

Baines,Kim; Western University, Canada Bas, Ahmet Deniz; COREM, Canada

Berg, John K.; United States

Bertsch, Kaila Morgen; University of Wisconsin Madison, United States

Braga, Maria Helena; University of Texas at Austin, United States

Braz Filho, Vicente Trindade; Vallourec/ Instituto Federal de Minas Gerais/ Universidade Federal de Ouro Preto, Brazil

Burla, Niharika; United States
Bustamante, Michele; United States

Camorlinga, Roberto; Asarco LLC, United States

Carlson, Krista; University of Utah, United States

Chang, TseWei; Citic Pacific, Australia

Chen, Chunlin; CSIRO Minerals, Australia

Contreras, Jonathan C.; RTI Laboratories Inc., United States

Coudert, Lucie; Université du Québec en Abitibi-Témiscamingue, Canada

Del Rio, Eduardo; United States

Desautels, Ryan D.; Oak Ridge National Laboratory, United States

Dionne, Justine; Institut National de la Recherche Scientifique, Canada

Djukic, Milos B.; University of Belgrade, Serbia and Montenegro

Doan-Nguyen, Vicky V.T.; The Ohio State University, United States
Dong, Xiangyang; Missouri University of Science and Technology, United States

Dufresne, Robert P.; Pultrusion Technique Inc., Canada

Eyzaguirre, J Carlos; FLSmidth, United States

Fehlauer, Emily D.; Imperial Oil, Canada

Fernandez-Baca, Jaime A.; Oak Ridge National Laboratory, United States

Fothergill, Jay; Canadian Intellectual Property Office, Canada

Garrison, Jennifer; Kansas City National Security Campus Honeywell, United States

Gemmill, William H.; United States

Gong, Yilun; University of Oxford, United Kingdom

Griffin, Mitchell; United States

Guo, Fuqiang; McGill University, Canada

Halls, Steven D.; United States 
Han, Yumei; Centre d'innovation Miniere de la MRC des Sources, Canada

Hilario, Felipe; Vale S.A., Brazil

Hyvarinen, Satu; Exotech Inc., United States

Jiang, Chuanyu; China Nerin, Canada

Jiang, Tao; Central South University, China

Koffler, Daniel; Hatch, Canada

Korzhavyi, Pavel A.; KTH - Royal Institute of Technology, Sweden

Levesque, Annie; Cegep de Sept-lles, Canada

Li, Liang; Kunming University of Science and Technology, China

Li, Lin; Queen's University, Canada

Li, Qing; Karlsruhe Institute of Technology, Germany

Li, Yi; Asia Pacific Electrode Technology Inc., Canada

Limaye, Sudhanwa P.; Technical University of Darmstadt, Germany

Liu, Xuan; Global Foundries, United States

Luo, Xia; Southwest Petroleum University, China

Makineni, Surendra Kumar; Max Planck Institute for Iron Research, Germany

Manzoor, Umair; School of Chemical and Materials EngineeringNational University of Sciences and Technology, Pakistan

Martin, Janet; Univar, Canada

Mathe, Mahlanyane K.; Council for Scientific and Industrial Research, South Africa

McClung, Craig; Rio Tinto Kennecott, United States

Mejilla, Antenor; Lubrizol Advanced Materials, Canada

Meqbel, Feras; Hi-Tech PMR, United States

Merrick, William H.; University of Toronto, Canada

Mills, Dewayne, L.; Chemours Company, United States

Miskimins, Jennifer; Colorado School of Mines, United States

Mohamed, Youssef AF; Dalhousie University, Canada
Mori, Manami; Sendai College, Japan

Moubarac, Rafic; Experco Composites Inc., Canada

Mueller, Kristin; Institut National de la Recherche Scientifique, Canada

Naanaa, Slim; Air Liquide, United States

Nyyssonen, Tuomo; Outotec Oyj, Finland

Oder, Tom N.; Youngstown State University, United States

Oliveira, Joana C. R. E.; University of Porto, Argentina

O'Malley, Ronald J.; Missouri University of Science and Technology, United States

Ortega, Dominic; University of North Texas, United States

Pan, Xiaoging; University of California, Irvine, United States

Park, Yeongdo; Dong-Eui University, South Korea

Potter, Barret G.; University of Arizona, United States

Prabhu, Rajkumar; Mississippi State University, United States

Putzig, Albert M.; Freedom-McMoRan Inc., United States

Qin, Yuanbin; Canada

Ranganatha, R.; SJC Institute of Technology, India

Ricotti, Leo; Meggitt Aircraft Braking Systems Corporation, United States

Robertson, Jessica; Haynes International, United States

Rocha, Sonia Denise F.; Universidade Federal de Minas Gerais, Brazil

Rodriguez, Rolando J.; Barrick Gold, Dominican Republic

Roy, Shibayan; Indian Institute of Technology Kharagpur, India

Safinski, Tomasz; Australian Nuclear Science and Technology Organisation, Australia

Sanchez, Cesar; AK Steel, United States

Sauber, Maziar E.; CanmetMINING, Canada

Savadogo, Oumarou; Polytechnique Montreal, Canada

Scheinman, Aviv; PEX-Industrial, Canada

Shaddix, Christopher; Sandia National Laboratories, United States
Silverstein, Ravit; University of California, Santa Barbara, United States

Simonnot, Marie-Odile; University of Lorraine, France

Singh, Swadesh Kumar; Gokaraju Rangaraju Institute of Engineering and Technology, India

Smith, Franc B.; Bodycote, United States

Smith, Ryan; California Polytechnic State University, United States

Tang, Bin; China Engineering Co., Ltd., China

Tevar, Amul; United States

Tian, Kun; United States

Tjayadi, Leonardi; North Carolina State University, United States

Tran, Lan Huong; Institut National de la Recherche Scientifique - Eau Terre Environnement Research Centre, Canada

Varone, Xavier; Novelis Switzerland SA, Switzerland

Vergara Hernandez, Hector Javier; Instituto Tecnologico de Morelia, Mexico

Videla, Alvaro R.; Pontificia Universidad Catolica de Chile, Chile

Viswanathan, Gopalakrishnan M.; Corrpro USA, United States

Wang, Yuanxi; United States

Wright, Ellen E.; Engineering Systems Inc., United States

Wu, Xinmin; Jinlong Copper, China

Xia, Liuyin; Saskatchewan Research Council, Canada

Yao, Suping; Cinina Engineering Co., Ltd., China

Yilmazer, Hakan; Yildiz Technical University, Turkey

Young, Rose; China Nerin Engineering Co., Ltd., China

Yuan, Duowei; University of Alberta, Canada

Zhihong, Liu; Central South University, China

Zhou, Jun; Tongling Non-ferrous Metals Group Holdings Co., Ltd, China

Zovko, Brodarac Zdenka; University of Zagreb, Croatia 